Check for updates

Cite this: RSC Adv., 2018, 8, 27709

Received 15th June 2018

Accepted 13th July 2018

DOI: 10.1039/c8ra05161e

rsc.li/rsc-advances

\section{Tuning the compatibility to achieve toughened biobased poly(lactic acid)/poly(butylene terephthalate) blends $\uparrow$}

\author{
Boon Peng Chang, (D) a Amar K. Mohanty (D) *ab and Manjusri Misra (D) ab
}

A series of sustainable biobased polymer blends from poly(lactic acid) (PLA) and poly(butylene terephthalate) (PBT) were fabricated and characterized. These blends are engineered to achieve optimal mechanical properties and toughness with a reactive epoxidized styrene-acrylic copolymer (ESAC) compatibilizer, and an ethylene-n-butyl-acrylate-co-glycidyl methacrylate (EBA-GMA) elastomer-based compatibilizer. The results showed that the tensile strength, modulus, flexural strength and modulus of the PBT increase, while the elongation at break and notched impact strength decrease after blending with the biopolymer PLA. The full co-continuity of PLA in PBT was confirmed at a 50/50 wt\% blend ratio. The droplet size of the PLA was reduced and the distinct phases of the blends were gradually diminished with the increasing content of the ESAC compatibilizer. The increase in the complex viscosity of the blends was due to the formation of PLA-g-PBT copolymers in the blend after addition of reactive compatibilizers. The incorporation of both compatibilizers in the blends led to superior notched impact strength in comparison to only a single compatibilizer used in the blends. The synergistic effect of both compatibilizers effectively reduces the PLA droplet size and improves the dispersion of PLA in PBT as evidenced by atomic force microscopy (AFM) topography observations. The high toughness of the blends corresponds to the formation of effective EBA-GMA structures and enhanced interfacial compatibilization due to the synergistic effect of the compatibilizers.

\section{Introduction}

Poly(butylene terephthalate) (PBT) is one of the high-volume usage commercial engineering plastics belonging to the aromatic polyester family with chemical functional groups similar to poly(ethylene terephthalate) (PET) and poly(trimethylene terephthalate) (PTT). Currently, PBT is widely used in many commercial applications due to its excellent properties such as high rate of crystallization, good moldability and fast mould cycle time, ${ }^{1}$ good mechanical and thermal properties where the service temperature can be as high as $140{ }^{\circ} \mathrm{C}$. Due to these beneficial properties, PBT becomes a promising blending component with other polymers to improve their original performance. This includes blending PBT with PET, ${ }^{2,3}$ polystyrene (PS), ${ }^{4}$ polyamide (PA), ${ }^{5}$ polypropylene (PP), ${ }^{6}$ polycarbonate (PC), ${ }^{7,8}$ and polyether imide (PEI) ${ }^{9}$ among others.

${ }^{a}$ Bioproducts Discovery and Development Centre, Department of Plant Agriculture, Crop Science Building, University of Guelph, 50 Stone Road East, Guelph, Ontario N1G 2W1, Canada.E-mail: mohanty@uoguelph.ca

${ }^{b}$ School of Engineering, Thornbrough Building, University of Guelph, 50 Stone Road East, Guelph, Ontario N1G 2W1, Canada

$\dagger$ Electronic supplementary information (ESI) available: TGA, heat deflection temperature measurement and digital images of tensile fractured blend are provide there. See DOI: 10.1039/c8ra05161e
Although PBT possesses many outstanding properties which are suitable for many engineering applications, it is very sensitive to crack tips or notch and the notched impact strength of pure PBT is quite low, approximately $36-40 \mathrm{~J} \mathrm{~m}^{-1}$. In order to improve the notched impact strength of PBT, numerous works have been carried out by blending PBT with different types of elastomer materials to toughen PBT under notched conditions. Different functional groups of elastomers such as ester, epoxide, maleic anhydride (MAH) and hydroxyl have been used to improve the notched impact strength of PBT. Some of the elastomers used to modify PBT and the highest notched impact strength value achieved are summarized in Table 1. The interface of PBT and elastomer can be further enhanced by grafting a reactive functional compatibilizer to further improve the notched impact strength. Functionalised rubber grafted with $\mathbf{M A H}^{\mathbf{1 0}}$ and epoxide groups ${ }^{\mathbf{1 1}}$ have been widely reported previously and show significant improvement as compared to the solely elastomer/PBT blend.

The plastic industry has successfully used different technology to develop sustainable biodegradable and biobased plastic materials in line with the sustainable development and environmental pollution issues emphasized globally. Development of biobased plastic for durable application has been growing every year accounting for $40 \%$ of the global plastic industry capacity in $2010 .^{19}$ The projected global biobased 
Table 1 Some of the works reported on the elastomer used, optimum loading and highest notched impact strength as achieved for PBT blends

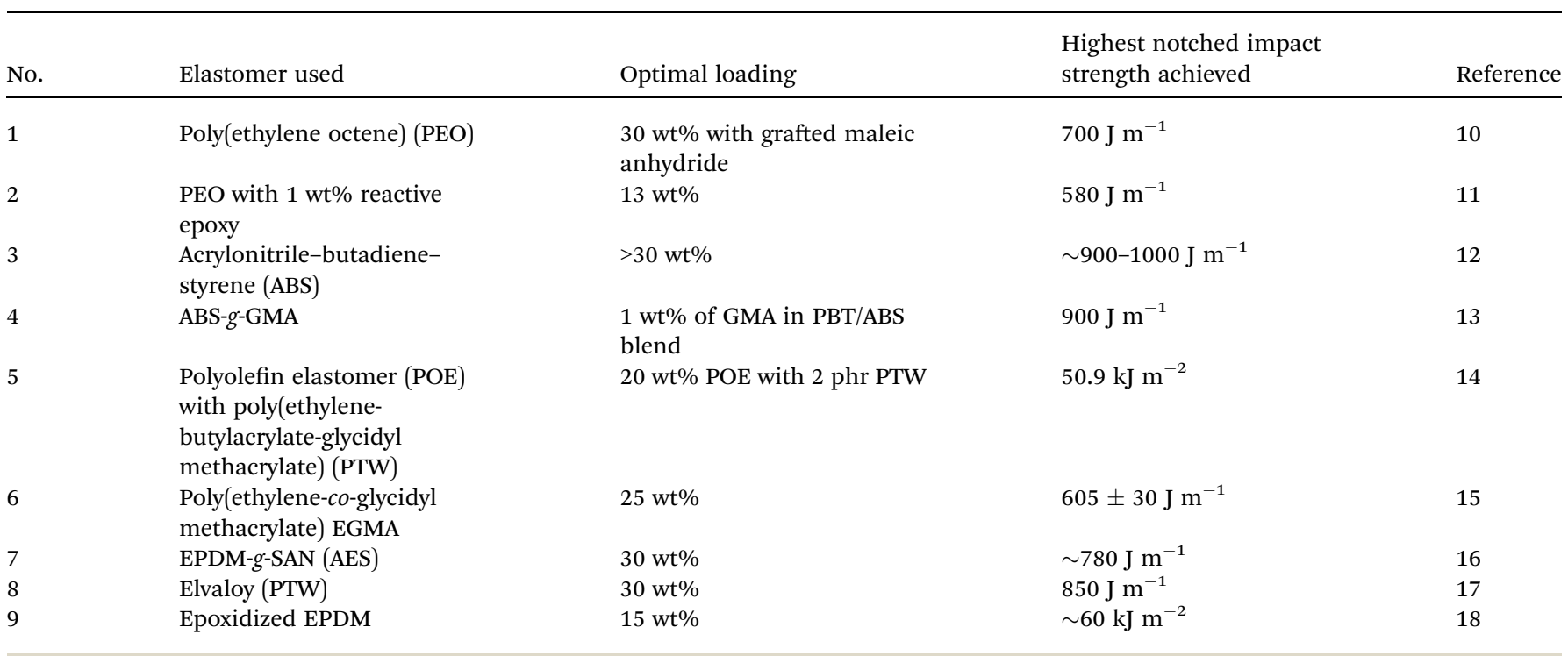

plastic is expected to grow by $20 \%$ of the global market capacity from 2017-2022. ${ }^{20}$ The majority of the important biobased polymers derived from sustainable feedstock have been produce by Braskem Company, Brazil.

Extensive research and improvement on the partially or fully biobased plastics to replace fully petroleum feedstock plastic have been implemented by many forefront plastic industries. Some of the market available biobased plastics are bio-PET, bioPP, poly(lactic acid) (PLA), polyhydroxyalkanoate (PHA), biohigh-density polyethylene (HDPE), bio-low-density polyethylene (LDPE) and others. Among these commercially available biobased polymers, PLA appears to be one of the most popular biodegradable polymer studied by many researchers and industries due to its excellent properties such as high mechanical strength, and modulus, transparency and non-toxic by-products. Blending of biodegradable polymers with petroleum based polymers allows development of partially biobased polymers with enhanced or desired properties at relatively low cost. $^{21,22}$ The work related to tailoring of the properties for biobased PLA blends to improve its performance have gained much interest in recent year. ${ }^{23-27}$ PLA is a good candidate to blend with PBT to form a biobased polymer as they are both from the polyester family. However, these two polymers are immiscible and incompatible to each other. ${ }^{28}$ Direct blending will not yield good properties for this blend. In addition, processing temperature of PLA is from $170-190^{\circ} \mathrm{C}$, whereas for PBT it is around $240-260{ }^{\circ} \mathrm{C}$. The processing temperature must be set at the range of $240-260{ }^{\circ} \mathrm{C}$ in order to melt and blend these two polymers together. It has been reported that the degradation rate of PLA increases rapidly above its melting temperature where a significant reduction of molecular weight was observed. ${ }^{29}$ The thermal degradation mechanisms include random main-chain scission, depolymerisation and oxidative degradation under oxygen environment during melt processing above $180{ }^{\circ} \mathrm{C} .^{30}$ Further increasing the processing temperature above $200{ }^{\circ} \mathrm{C}$ leads to the formation of cyclic oligomers and transesterification degradation. ${ }^{31}$ The mechanical performance of PLA will decrease dramatically after degradation. Hence, the degradation issue of PLA when blending with engineering polymers at elevated processing temperature is a main challenge restricting the commercial fabrication of this biobased blend by the industry sector.

In order to minimize the degradation problem of PLA when processing at high temperature, many researchers have proven the effectiveness of chain extender with the idea of reconnecting the broken chains of PLA and hence leading to recovery and prevention in the molecular weight reduction of PLA. Some of the chain extenders that have been studied and reported to be effective in controlling the degradation of PLA are polycarbodiimide (PCDI), ${ }^{32}$ tris (nonylphenyl) phosphite $(\mathrm{TNPP})^{33}$ and epoxy functionalized styrene-acrylate copolymer. ${ }^{21,34-36}$ Najafi et al. ${ }^{37}$ reported that styrene-acrylate copolymer with reactive epoxy is more efficient and effective in increasing the thermal stability of PLA-clay nanocomposites under the study conditions as compared to PCDI and TNPP. The multi-functional epoxy compound in the styrene-acrylate copolymer can react easily with hydroxyl and carboxyl end groups in polyester especially in PLA. ${ }^{38,39}$ Hence, it is an effective compatibilizer as well as chain extender to compatibilize PLA and PBT. Only a few works have reported on the biobased blend of PLA and PBT thus far. The PLA/PBT blend is immiscible but they are having a certain degree of compatibility due to the physical interactions between the polyesters functional groups. ${ }^{28} \mathrm{Kim}$ et al. ${ }^{40}$ studied the crystallization rate and degradability of the PLA/PBT blend with para-phenylene diisocyanate (PPDI) chain extender. They reported that the crystallization rate of the PLA phase was improved, and the degradation rate was prolonged. There are some works reporting on polymerization of PLA-PBT block copolymers via the transesterification and ring opening processes. ${ }^{41}$ In a recent study, the properties of biodegradable PLA blended with 3, 5 and $10 \mathrm{wt} \%$ of PBT with addition of ethylene-glycidyl 
methacrylate copolymer as compatibilizer was reported by Santos et al. ${ }^{42}$ They reported enhanced mechanical properties of the PLA due to the formation of nanometer-size PBT dispersed phase in the blend. In all the works mentioned discussed above use PLA (biodegradable-based polymer) as the major matrix component and PBT (petroleum-based polymer) as the minor blend component to improve the properties and crystallization behaviour of PLA.

However, in the present work, focus is on the incorporation of the biodegradable polymer, PLA, into the petroleum-based polymer, PBT, to acquire a novel high-biobased content (30$40 \mathrm{wt} \%$ ) polymer blend. In addition, no work has reported on the mechanical performances of this high biobased PLA/PBT blend which is very important to industry to consider in producing the blend into a possible commercial biobased product to replace petroleum-based products in the market. The blending of high PLA content usually gives low impact toughness due to the brittleness of PLA. In this study, the compatibilization of PLA and PBT with reactive epoxy functionalized compatibilizers is reported. PLA was used as the biobased component incorporated in PBT matrix at weight ratio of $10 / 90,20 / 80,30 / 70,40 / 60$ and 50/50 blends. Small amounts of epoxy functionalized styrene-acrylate copolymer compatibilizer were added in the blend to compensate for the degradation of PLA and at the same time induce interactions between PLA and PBT. The toughness of the blends was further improved with elastomer-based poly(ethylene- $n$-butylacrylate-co-glycidyl methacrylate) (EBA-GMA) compatibilizer. The PLA/PBT blends were engineered to achieve optimal mechanical properties and toughness with the two compatibilizers. Significant biobased content of the PLA/PBT blends in this work can reduce the dependency on petroleum-based resources which in turn promote sustainable development and leads to significant reduction in greenhouse gas emission to the environment.

\section{Materials and experimental details}

\subsection{Materials}

The thermoplastic polyester PBT pellet grade 2000-3 is a product from Ticona Engineering Polymer, Celanese, Ticona with the density of $1.31 \mathrm{~g} \mathrm{~cm}^{-3}$. The PLA Ingeo biopolymer 3251D injection moulding grade of NatureWorks, LLC, USA with the density of $1.24 \mathrm{~g} \mathrm{~cm}^{-3}$ was used. Two reactive epoxybased functional compatibilizers were used in this study. The first compatibilizer is epoxy functionalized styrene-acrylate copolymer (ESAC) compatibilizer with the trade name of Joncryl grade ADR-4368C, supplied by BASF (BASF, Ludwigshafen, Germany). According to the BASF manufacturer data, it consists of multi-functional polymer reactive groups with approximately $285 \mathrm{~g} \mathrm{~mol}^{-1}$ weight of reactive epoxy functional group. The second compatibilizer is poly(ethylene- $n$-butyl-acrylate-co-glycidyl methacrylate) (EBA-GMA) compatibilizer with the tradename of Elvaloy 1224AC and was supplied by DuPont. The EBA-GMA compatibilizer has approximately $5.25 \mathrm{wt} \%$ of reactive epoxy functional group (glycidyl methacrylate, GMA).

\subsection{Preparation of the PLA/PBT blends}

The PLA/PBT blends and the blends with different compatibilizers at different ratios of composition were processed using DSM-Xplore twin screw micro-compounder, from Netherlands. The length/diameter $(L / D)$ ratio dimension of the screws used was $150 \mathrm{~mm}$ to $18 \mathrm{~mm}$ respectively. The mixing extrusion barrel volume of the machine was $15 \mathrm{~cm}^{3}$. The PLA and PBT pellets were dried in an oven at $80{ }^{\circ} \mathrm{C}$ overnight before processing. The PLA and PBT were blended in the extrusion barrel at the processing temperature of $250{ }^{\circ} \mathrm{C}$ with the screw speed of $100 \mathrm{rpm}$. The mixing process took 2 mins for every blend in the barrel and the molten blend was extruded out into a preheated cylinder. The molten blend was then transferred to injection moulding process using DSM-Xplore micro-injection moulding. The standard test samples of tensile, flexural and notched impact according to the ASTM standard were moulded and obtained after 20 seconds of holding time with 10 bar of the pressure in the injection moulding process and $30{ }^{\circ} \mathrm{C}$ of mould temperature. The same procedure was repeated for the PLA/PBT blend with compatibilizers. Different amounts of compatibilizers (ESAC, 0.3-1.0 phr and EBA-GMA 5-20 wt\%) were studied and optimized in the blends. Due to the high weight percent of reactive epoxy groups in the ESAC compatibilizer, a very small amount of this compatibilizer is usually used as compared to EBA-GMA. All the samples were conditioned at a temperature of $23{ }^{\circ} \mathrm{C}$ and relative humidity of $50 \%$ for at least 40 hours after processing according to ASTM D618 prior to testing.

\subsection{Mechanical test}

Tensile properties, flexural properties and impact strength test were carried out to evaluate the mechanical properties of the PLA/PBT blends. The standard of the mechanical tests were followed according to ASTM D638 (Type IV), D790 and D256, respectively. The tensile and flexural tests were performed using Instron 3382 Universal Testing Machine. The tensile test was performed with a crosshead speed of $5 \mathrm{~mm} \min ^{-1}$ and the flexural test was carried out at crosshead speed of $14 \mathrm{~mm} \mathrm{~min}^{-1}$ on $52 \mathrm{~mm}$ span length setup with flexural strain of $5 \%$ extension, unless early failure occurred. Notched Izod impact test was carried out using a TMI 43-02 Monitor Impact Tester (Testing Machines Inc., New Castle, DE, USA). The samples were notched in a notch cutter according to ASTM D256 notched depth after processing. All the mechanical data reported were obtained from a total of 5 specimens for each sample and the mean and standard deviation were reported.

\subsection{Co-continuity analysis}

The co-continuity development of PLA phase in PLA/PBT blend was investigated using Soxhlet extraction method. This method has been widely used by researchers to confirm the cocontinuous phase of polymer blends quantitatively. ${ }^{43-45}$ Chloroform with $99.5 \%$ purity was used as an extractor solvent to extract the PLA phase from the PBT matrix. Approximately $2 \mathrm{~g}$ of each sample were cut from the grip part of the dumbbell specimen and placed into a Soxhlet extraction apparatus. The 
extraction was carried out for 24 hours to ensure complete removal of the PLA fraction. After extraction process was completed, the samples were dried in a vacuum oven at $85{ }^{\circ} \mathrm{C}$ for 24 hours. The percentage of PLA continuity is calculated as in eqn (1)

$$
\% C_{\mathrm{PLA}}=\frac{m_{\mathrm{b}}-m_{\mathrm{a}}}{m_{\mathrm{b}} \times w} \times 100 \%
$$

where $m_{\mathrm{b}}$ is the mass before extraction, $m_{\mathrm{a}}$ is the mass after extraction and dried and $w$ is the PLA weight fraction.

\subsection{Shear rheology}

The shear rheology properties of the PLA/PBT blends were measured using Anton Paar rheometer modelled MCR-502. The blends were cut into a disk shape with a dimeter of $25 \mathrm{~mm}$ and place between the parallel plates setup with a zero gap of $1 \mathrm{~mm}$. The shear deformation frequency sweeps were performed at a shear strain of 1\% with a frequency range of 0.1-628 $\mathrm{rad} \mathrm{s}^{-1}$. The pure PBT and PLA/PBT blends were tested at a temperature of $235{ }^{\circ} \mathrm{C}$ while the pure PLA is tested at $190{ }^{\circ} \mathrm{C}$ to avoid severe degradation. All tests were conducted under an oxygen atmosphere and the shear rheology properties i.e. complex viscosity, storage modulus and loss modulus acquired were reported.

\subsection{Impact fractured morphology}

The impact fractured surfaces of the PLA/PBT blends were examined using a Phenom ProX desktop scanning electron microscope (SEM) from Phenom World. All the impact fractured samples were coated with a thin gold layer with a Cressington Sputter Coater 108 auto vacuum sputter chamber.

\subsection{Atomic force microscopy (AFM)}

The internal topography of the PLA/PBT blends with single and hybrid compatibilizer were analysed using a multimode 8 AFM from Bruker Nano Inc. (USA). The observation and imaging acquired were carried out with the aid of Nanoscope $\mathrm{V}$ controller and Nanoscope Software (version 8.15). The AFM was carried out in Peak Force (PF) mode with TAP525A silicone cantilevers having a spring constant of $200 \mathrm{Nm}^{-1}$. The imaging was scanned with Derjagin, Muller, Toropov (DMT) modulus measurement mode with the scanning rate and scanning line of $0.2 \mathrm{~Hz}$ and 500 respectively. Before scanning, the samples surface was polished using a Leica Ultracut, Wetzler, Germany UC7 ultra-microtome with a sapphire knife to create a smooth surface profile.

\section{Results and discussion}

\subsection{Mechanical properties of the PLA/PBT blends}

Fig. 1 shows the tensile properties and notched impact strength of various PLA/PBT blends compositions. The tensile strength of PBT showed increases in value after addition of PLA up to 30 wt\% content (Fig. 1a). The experimental value starts to decrease at $40 \mathrm{wt} \%$ of PLA blend content. The interaction between the binary polymers blend can be roughly predicted in the tensile strength of the blends. A poor interaction acts as flaw and stress concentration which results in reduction of tensile strength after blending. The slight increase in tensile strength of PLA/PBT blends indicates a good interaction between these two polymers in the blends at low content of PLA (<30 wt\%). A good interaction and compatibility between functional groups of PLLA and PBT containing PLLA as major component was also reported by Lorenzo et al. ${ }^{28} \mathrm{~A}$ gradual deviation from the rule of mixture line of tensile strength showed their poor interaction and the degree of immiscibility increases between the two polymers in the blend when the PLA content in PBT was above $30 \mathrm{wt} \%$. In terms of modulus, the tensile modulus value shows an increasing trend with the increasing of PLA content in PBT. This can be attributed to the high modulus in nature of PLA. Hence, the modulus of the blends increases with the addition of PLA. In comparison to the rule of mixture line in the graphs, it can be noticed that the experimental values are near to the rule of mixture line at low content of PLA in PBT blend compositions. The elongation at break decreases dramatically after incorporation of PLA in PBT. This is due to the low ductility of PLA behaviour and interruption of the continuous phase of PBT after blending. Hence, the percentage elongation at break of the PLA/PBT blends remained low.

The notched impact strength of PLA/PBT blends showed a variation of mean value in a range of $10-30 \mathrm{~J} \mathrm{~m}^{-1}$. It can be seen that the notched impact strength of the 20/80 and 50/50 PLA/PBT blends are lower than that of pure PBT and PLA. The blend compositions at 10/90, 30/70 and 40/60 showed a slightly higher impact strength value than pure PLA which might be due to the different blends microstructures forming (refer to SEM part for the morphology transition). It has been known that the addition of PLA in the polymer blend usually reduces the impact strength of the blend due to the brittleness of the PLA in nature with low crack propagation energy and structural integrity interruption of the matrix in the blend. ${ }^{46,47}$ In addition, the thermodynamic immiscibility between PLA and PBT resulted in poor interfacial adhesion. Therefore, it is necessary to further improve the toughness of this biobased blend for practical applications in industry perspective.

The SEM observations on the impact fractured surfaces of PLA/PBT blends with different blend ratios and its schematic drawing diagram are shown in Fig. 2a-f and 3 respectively. It can be seen that there are two different phases present in the fractured surfaces which shows the immiscibility between the two PLA and PBT polymers after blended. In general, the impact fractured surfaces of all the PLA/PBT blends are relatively smooth and no plastic deformation was observed which indicates a brittle behaviour of the blends upon impact. Hence, the impact strength of the blends is low. The droplets of PLA phases act as a dispersed phase (droplets) and distribute in the PBT matrix in the blends at low loading content of PLA i.e. 10/90 and 20/80 PLA/PBT blends (Fig. 2b and c). It can be seen that there are many empty cavities after the impact test on the fractured surfaces. This is due to the clean pull-out of the PLA droplets from the PBT matrix upon impact which indicates weak interaction and immiscibility between PLA and PBT. The increase in size of the PLA droplets can be seen with the increasing content of PLA in the blend. This can be due to the coalescence of the 

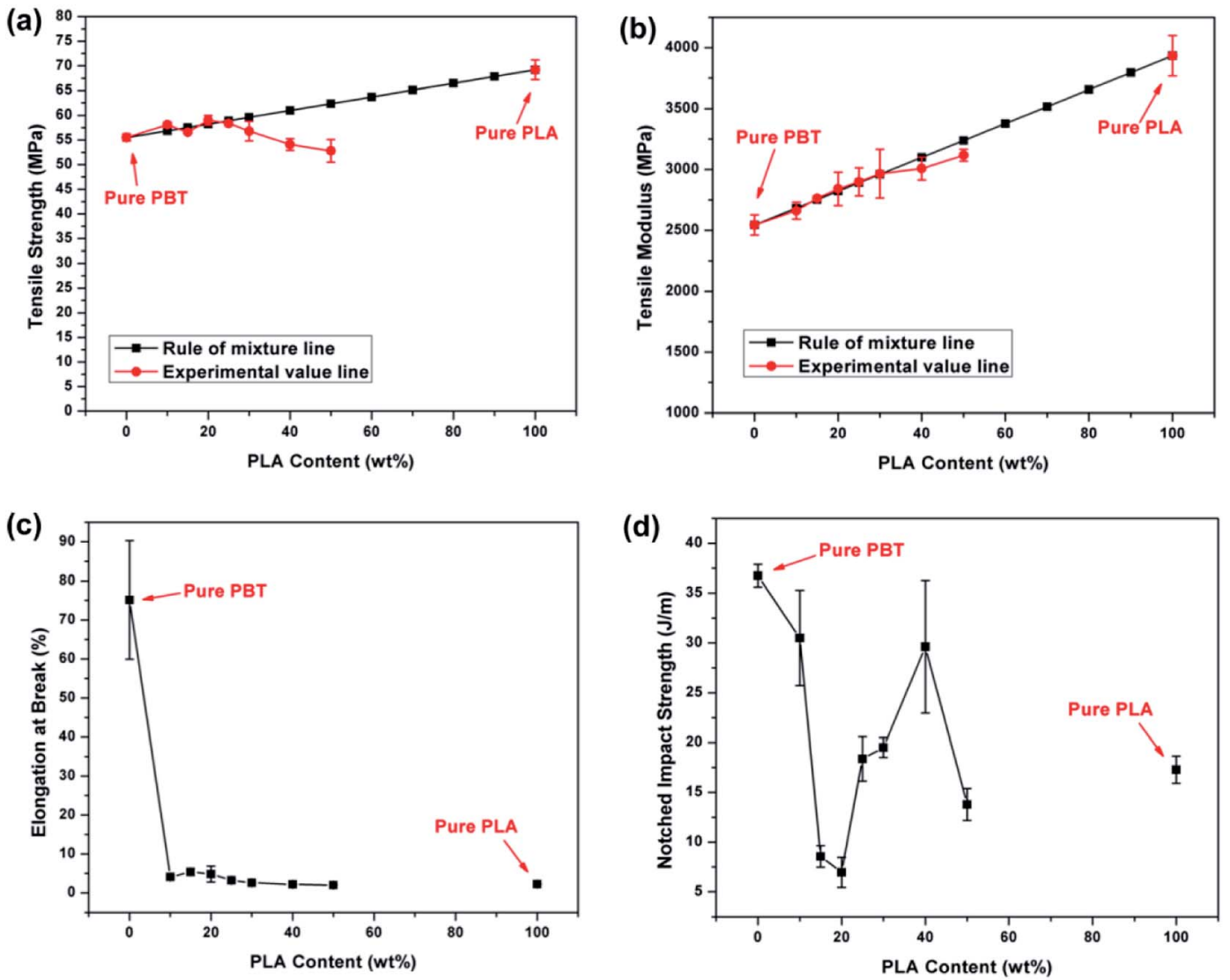

Fig. 1 Tensile properties of PLA/PBT blends at different weight fraction of PLA in PBT; (a) tensile strength, (b) tensile modulus, (c) elongation at break and (d) notched impact strength.

PLA droplets when the PLA content is increasing. The PLA droplets started having larger coalescence structures at 30/70 PLA/PBT blend (Fig. 2d). The increase in the size of the coalescence structures and formation of co-continuous PLA phases are observed in 40/60 of PLA/PBT blend (Fig. 2e). At 50/50 PLA/ PBT blend ratio, the co-continuous phases of PLA become dominant due to high loading of PLA in the blend and phase conversion occurred to PBT which changed from a continuous phase to droplet phase in the blend (Fig. 2f). A clearer view on the transformation of the impact fractured morphology of the PLA/PBT blend is shown in the schematic diagram of in Fig. 3.

The co-continuous phase development of PLA in the blends was further investigated quantitatively using solvent extraction method as shown in Fig. 3. As seen in the graph, only a negligible amount of the PLA phases was extracted out from the blend at 10/90 and 20/80 of PLA/PBT blends ratio. The PLA droplets remain encapsulated by the PBT due to the small amount of PLA phase present in the PBT matrix. At 30/70 wt\% PLA/PBT blend ratio, the PLA droplets coalesced to form partial continuous phases and a significant amount of PLA phases were extracted out from the PBT matrix. The co-continuity percentage of PLA continues to increase with the increasing weight percent of PLA in the PBT blend from 30-50 wt\%. The PLA/PBT blend ratios of 30/70 and 40/60 can be referred to partial continuity of PLA in the PBT phase. The full continuity PLA phase was observed at 50/50 PLA/PBT blend ratio where $98 \%$ of the PLA phase was extracted out. In order to rationalize the high biobased content in PBT of this work, substantial amounts of PLA in PLA/PBT blend ratios at 30/70 and 40/60 were further characterized and enhanced with compatibilizers.

\subsection{Effect of ESAC compatibilizer on the mechanical properties of the PLA/PBT blends}

Fig. 4 shows the effect of ESAC compatibilizer on the mechanical properties of the PLA/PBT blends. It can be seen that the tensile strength and tensile modulus were increasing with the increase of ESAC compatibilizer content (Fig. 4a and b). In general, the 40/60 PLA/PBT blends showed slightly higher tensile strength and tensile modulus as compared to the 30/70 blends at all loading of ESAC. The improvement in the mechanical strength and modulus of the blends were mainly due to better interfacial adhesion between PLA and PBT phase after compatibilization. The branching effect of ESAC also causes an increase in entanglement density of the chains and thus further stiffening the blends. ${ }^{48,49}$ Therefore, the tensile strength and tensile modulus of the blends were increased with increasing ESAC content.

A gradual increase in percentage elongation was observed with the increasing content of the compatibilizer. A significant increment in percentage elongation was observed at $1.0 \mathrm{phr}$ of 

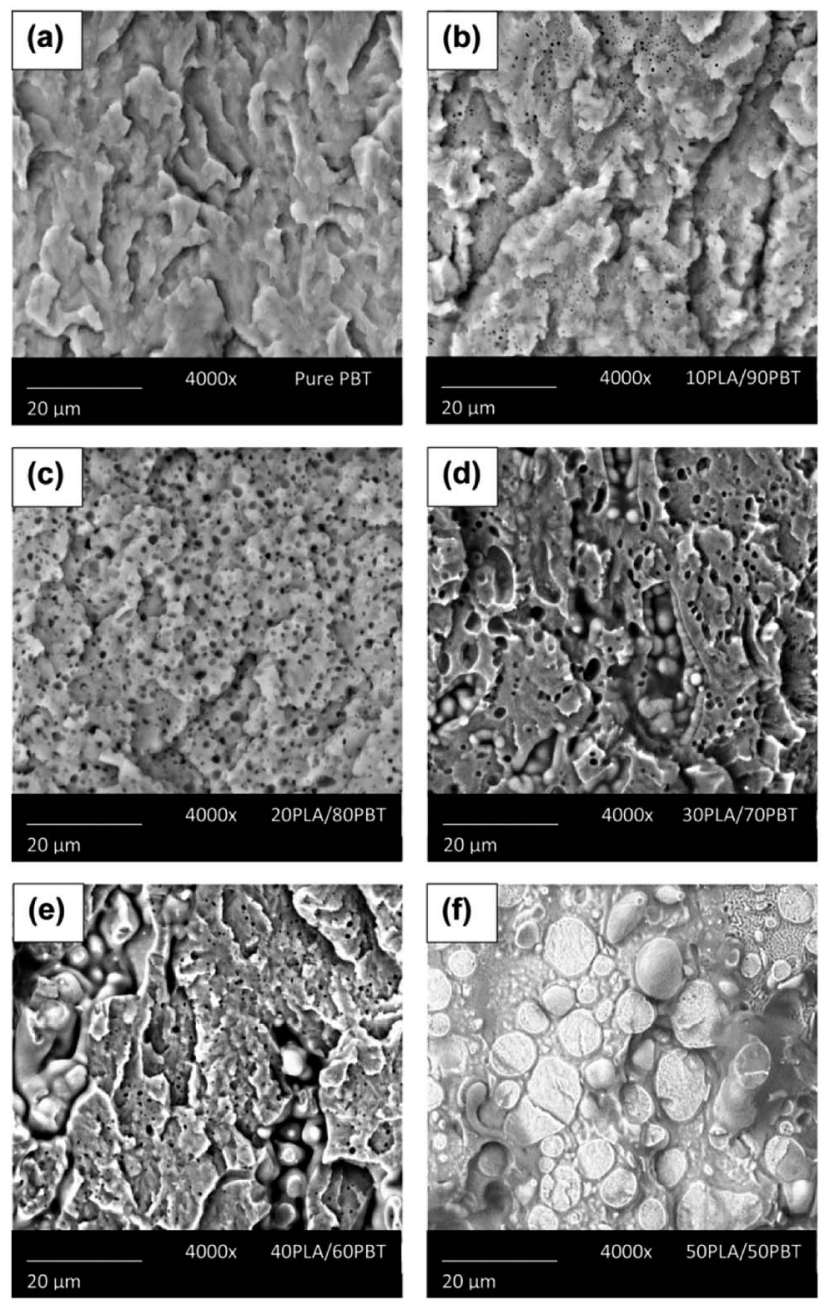

Fig. 2 SEM micrographs of impact fractured surfaces of PLA/PBT blends with different wt\% of blend ratios (a) pure PBT, (b) 10/90, (c) 20/ 80, (d) $30 / 70$, (e) $40 / 60$ and (f) $50 / 50$.

ESAC in both 30/70 and 40/60 PLA/PBT blends as can be seen in Fig. 4c. The blends experienced long necking before break when sufficient amount of ESAC compatibilizer was added (Fig. 4d). This enhancement in ductility of the blend is due to the formation of a long chain branch structure and chains interaction between PLA and PBT after compatibilization. A significant increase in the percentage elongation ( $\sim 500 \%)$ of the PLA/ poly(butylene adipate-co-terephthalate) (PBAT) blends with addition of ESAC was also reported by Dong et $a l .{ }^{50}$ The positive effect of ESAC compatibilizer on the elongation at break were also shown in PBAT/PLA ${ }^{34}$ and poly(butylene succinate)-co-adipate (PBSA)/PLA ${ }^{38}$ biodegradable blends. The change in morphology of the blends phases after compatibilization was also one of the reasons that resulted in an enhanced of elongation at break.

The compatibilizer effect is not pronounced at $0.3 \mathrm{phr}$ for both 30/70 and 40/60 PLA/PBT blends ratio (Fig. 4c). The amount of chain extender content may be insufficient for the 40/60 PLA/PBT blend when the loading is less than $0.7 \mathrm{phr}$. However, the substantial increased in elongation at break of



Fig. 3 Quantitative analysis of the PLA percentage co-continuity development in PLA/PBT blends using solvent extraction method (schematic diagram: PLA phase (red in color), PBT phase (blue in color)).

30/70 PLA/PBT blend at $0.5 \mathrm{phr}$ of compatibilizer was observed. This shows that it is sufficient to enhance the interfacial properties of this blend ratio at $0.5 \mathrm{phr}$ ESAC. This can be due to the lesser amount of PLA in this blend as compared to $40 / 60$ blends. It was noticed that the elongation at break of the blends shows high standard deviation at $0.7 \mathrm{phr}$ of ESAC. The tensile fractures at this loading are inconsistent due to the formation of strain-hardening at outer layer of some samples which created long necking before samples broke. The digital image showing the development of strainhardening of the blend samples was given in the ESI Fig. S1. $\dagger$ This phenomenon becomes consistent at $1.0 \mathrm{phr}$ of ESAC where all the samples exhibited long necking propagation upon stretching. A significant improvement in the elongation at break was observe at $1.0 \mathrm{phr}$ for both 30/70 and 40/60 PLA/PBT blends showing a decent amount of compatibilizer content in the blends. The effect of ESAC compatibilizer in various polymer blends have been reported by a number of researchers and the optimal loading of the ESAC chain extender might be vary with the different polymer blend system as well as the blending ratio. ${ }^{35,51,52}$ Walha et al. ${ }^{35}$ reported that the addition of 0.7 to $1.0 \mathrm{phr}$ of ESAC is more pronounced in improving the blends properties as compared to 0.3 and 0.5 phr of ESAC compatibilizer in the PLA and polyamide 11 (PA11) blends. The less effective in the performance of the blend with the compatibilizer is mainly due to the insufficient compatibilization between the two polymers. The percentage elongation at break of 40/60 PLA/PBT blend was improved significantly from $2.2 \%$ to $141.4 \%$ at $1.0 \mathrm{phr}$ of ESAC loading (Fig. 4c). Approximately $~ 6300 \%$ increment on the elongation was achieved after addition with $1.0 \mathrm{phr}$ of ESAC compatibilizer in the 40/60 PLA/PBT blend. The possible chemical reactions occurring between PLA, PBT and ESAC during melt blending are shown in Fig. 5. The hydroxyl and 
(a)

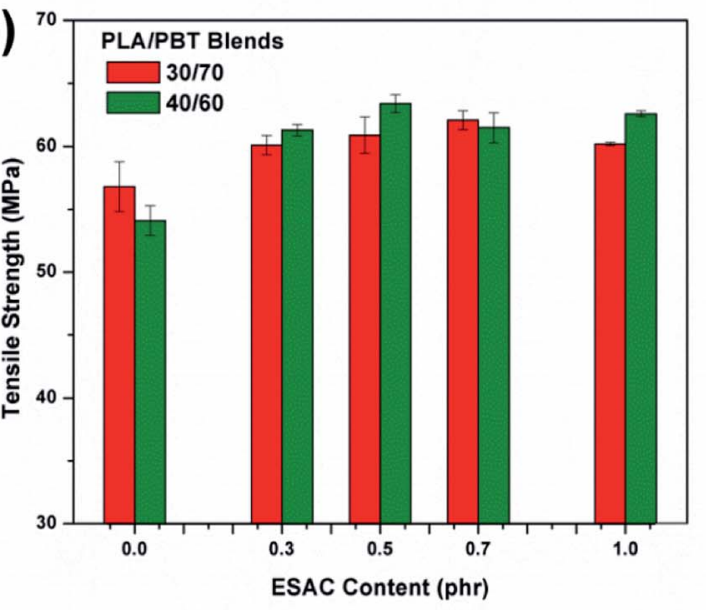

(c)

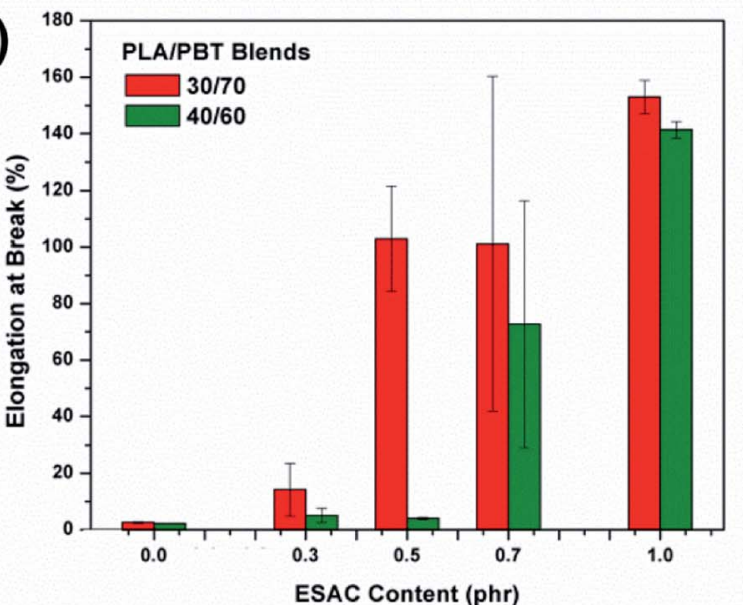

(e)

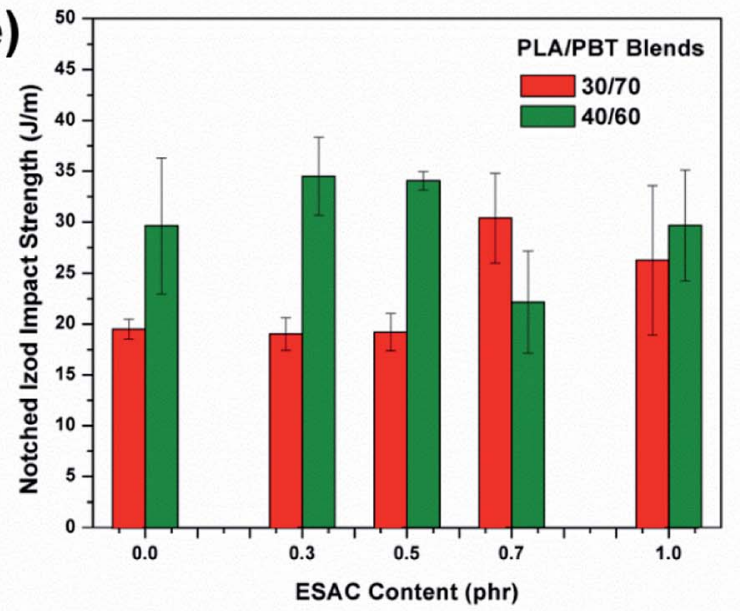

(b)
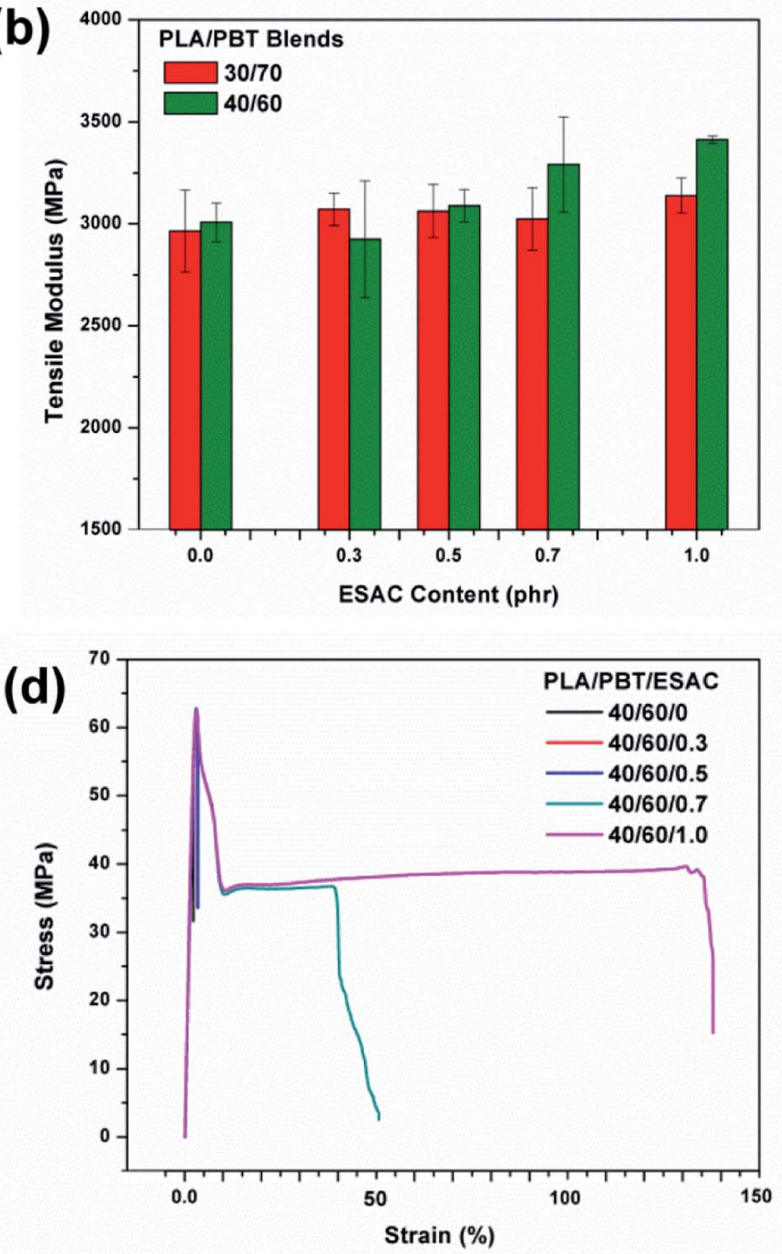

(f)

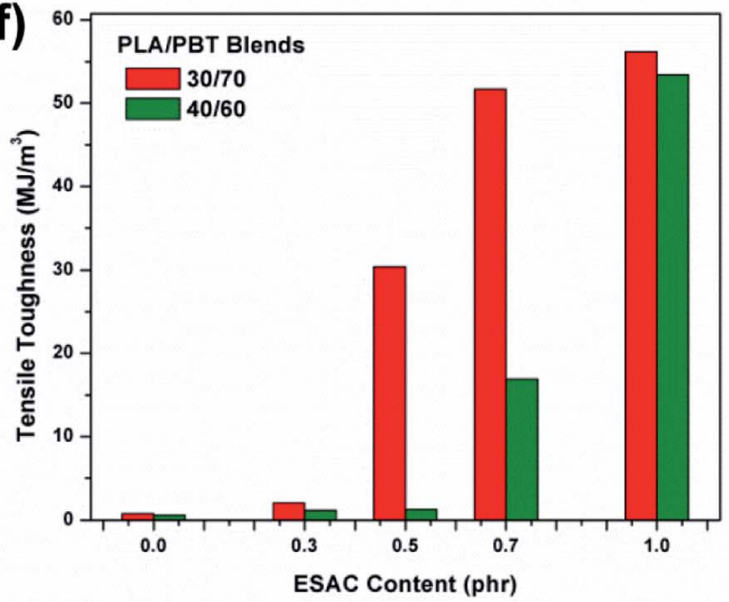

Fig. 4 The effect of increasing content of ESAC compatibilizer on the mechanical properties of PLA/PBT blends, (a) tensile strength (b) tensile modulus, (c) elongation at break (d) stress-strain curve (e) notched lzod impact strength and (f) tensile toughness.

carboxyl groups in the PBT and PLA may react with oxirane rings in the ESAC through ring opening reactions forming covalent bonds. ${ }^{34,53}$ However, PLA might be more reactive with ESAC than PBT. This is due to the severe chain scission of PLA under high temperature processing which provides high amounts of terminal ends to react with ESAC. It has been reported that the ESAC epoxide groups react more readily with carboxyl groups than with hydroxyl groups. ${ }^{54-56}$

In regard to the notched Izod impact strength, no significant improvement was observed after addition of ESAC compatibilizer in the blends (Fig. 4e). The notched impact strength values remain almost constant with the increase of the ESAC content. On the other hand, the tensile toughness (integral areas under 


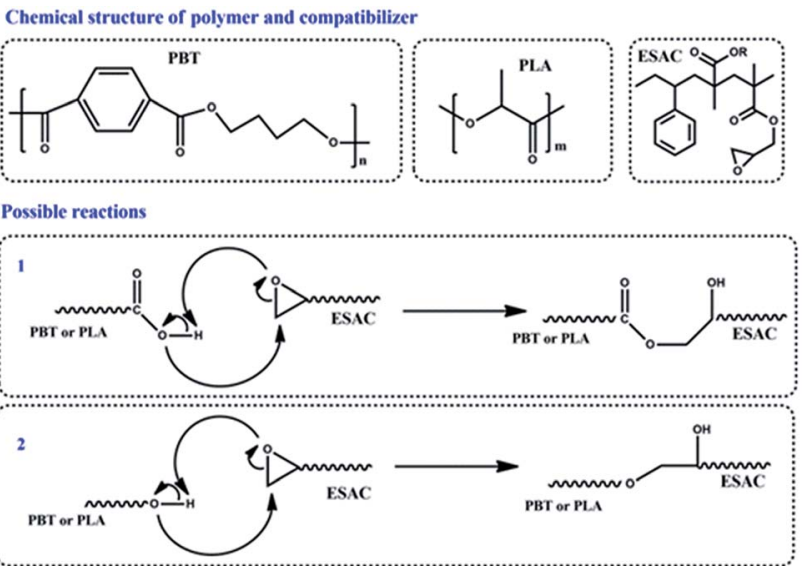

Fig. 5 Possible reaction between PLA, PBT and ESAC during melt blending ${ }^{31,32,46}$

the stress-strain curves) of the blends increased with increasing content of ESAC (Fig. 4f).

The tensile toughness demonstrated a similar trend to the observed elongation at break due to their direct correlation. The high toughening efficiency in tensile toughness can be due to the synchronicity of effective compatibilization and long-chain branching of the ester groups in the PLA and PBT after compatibilization. The branching in long-chain aids to increase the entanglement density and restrict the slippage of the chains upon elongation. ${ }^{38}$ These observations suggest that the ESAC compatibilization effects are not capable in improving the toughness of the blends under high strain rate test (impact test). However, tremendous increase in toughness can be achieved with appropriate amount when tested under low strain rate (tensile test).

Fig. 6 presents the SEM impact fractured morphology of the blend after being compatibilized with ESAC. The addition of ESAC results in significant changes of the impact fractured morphology of the blends where the phase separation of the PLA and PBT gradually diminished with increasing ESAC content in the blends. The two distinct co-continuous phases were not observed in the PLA/PBT blend with $1.0 \mathrm{phr}$ of ESAC loading (Fig. 6e). This can be due to the reduction in surface tension between PLA and PBT and results in reducing the size of the dispersed phase after compatibilization. ${ }^{34}$ An improvement in the wettability of the surface between thermoplastic starch and PLA after addition of ESAC was also reported by Zhang et al. ${ }^{57}$ The reduction in the dispersed phase domain size shows that the compatibility between the two polymer phases was improved. Better dispersion and uniformity of the PLA droplets in the PBT matrix was observed with an increase in the compatibilizer content. In addition, the interaction of the polymers was improved with less interfacial gaps between the two immiscible phases (Fig. 6e).

\subsection{Shear rheological of PLA/PBT blends}

Fig. 7 presented the logarithm of the complex viscosity, storage modulus and loss modulus as a function of angular frequency
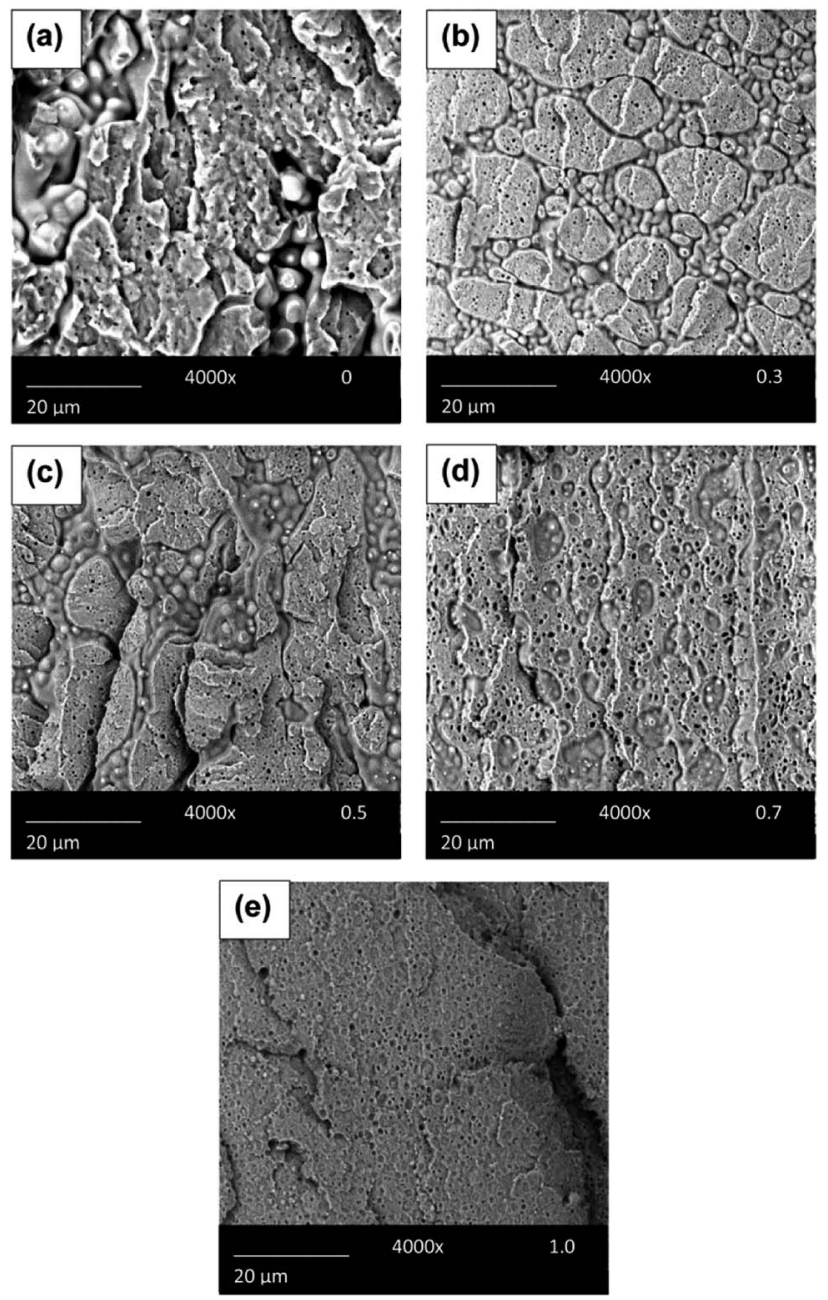

Fig. 6 SEM micrographs of impact fractured surfaces of 40/60 PLA/ PBT blends with different content of ESAC compatibilizer (a) 0 , (b) 0.3 phr, (c) $0.5 \mathrm{phr}$, (d) $0.7 \mathrm{phr}$, and (e) $1.0 \mathrm{phr}$.

at different ratio of the PLA/PBT blends. It can be seen that the complex viscosity of PLA was lower about 10-fold when tested at $235^{\circ} \mathrm{C}$ as compared to at $190{ }^{\circ} \mathrm{C}$ (Fig. 7a). This indicates that PLA undergoes severe degradation at temperatures higher than $20{ }^{\circ} \mathrm{C}$. The reduction in complex viscosity is mainly due to the chains degradation and loss in molecular weight. The loss in inter- and intra-molecular forces leads to higher chains mobility movements. ${ }^{36}$ Hence, the blending of PLA with PBT at high processing temperature will cause the degradation of PLA and proper chain extender or stabilizer additives must be used in order to minimize the degradation of PLA during processing at high temperature. It was noticed that the melt viscosity of PBT is slightly higher than PLA. However, both PLA and PBT are having very low melt strength with the complex viscosity value in the range of approximately 100-200 Pa s (Fig. 7a). The low melt viscosity resulting in a reduction in some of the mechanical properties $^{58}$ and also limits its processing methods. The melt flow behaviour of both PLA and PBT exhibited newtonian flow behaviour at low shear rate. The flow behaviour exhibited shear thinning after $100 \mathrm{rad} \mathrm{s}^{-1}$ of angular frequency. This indicates 

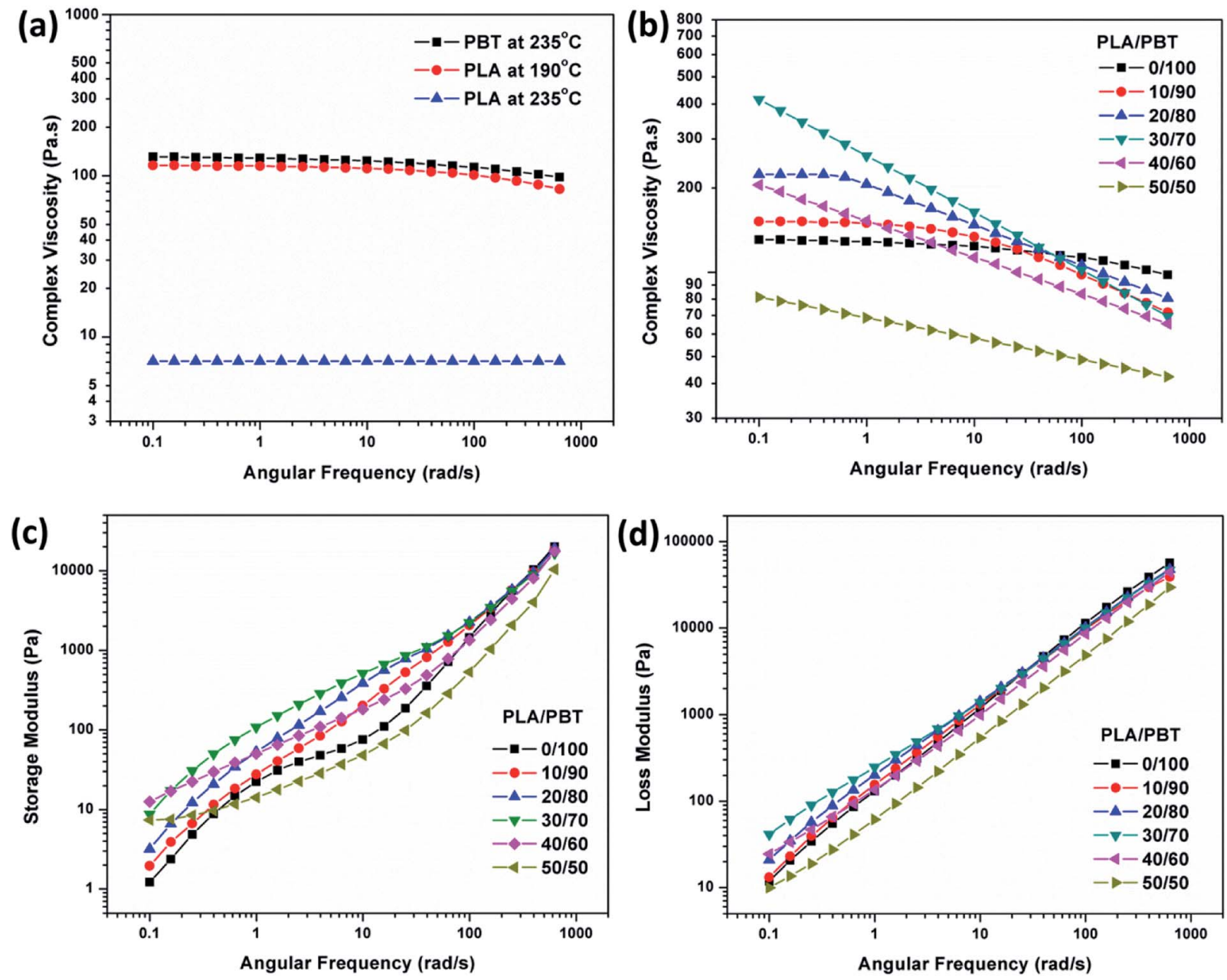

Fig. 7 (a) and (b) The complex viscosity, (c) storage modulus and (d) loss modulus as a function of angular frequency at different wt\% ratios of PLA/PBT blends.

that the viscosity of both PLA and PBT are sensitive to the high shearing action upon melting. The shear thinning behaviour becomes more pronounced with the increasing content of PLA in the blends (Fig. 7b). The PBT becomes sensitive to shearing action after blending with PLA. The deviation from the newtonian behaviour after blending could be due to the large difference of the melt viscosity between PLA and PBT which yields a different morphology as compared to the homopolymer structures.

There are two different melt-flow behaviours that can be seen for the blends. The interactions between blend components could be interpreted at the low shear frequency region, while the intermediate and high shear frequency regions are usually affected by the entanglement density, molecular weight, branching and phase miscibility. ${ }^{59}$ At high shear amplitude frequency, the complex viscosity of the blends was lower than pure PBT. This can be attributed to the degradation of PLA and ease of slip between the blend at high shear amplitude. The low viscosity of PLA at high processing temperature could increase the flowability of the blends. ${ }^{60}$ On the other hand, the complex viscosity of the PBT was gradually increased at low angular frequency after blending with PLA. The increase in complex viscosity shows there is a certain degree of physical interaction (hydrogen bonding) between PLA and PBT at low shear frequency even though they are incompatible to each other. It was believed that the droplets of PLA in the PBT matrix change the flow behaviour of PBT molecular chains in the melt state. As the droplets size increases (as can be seen in Fig. 2), the higher restriction on PBT chains can be expected due to differences in surface tension of the two polymers. However, the complex viscosity showed a decreasing trend above $30 \mathrm{wt} \%$ of PLA in the blend. This reduction in the viscosity was due to the increasing of dominant phase of PLA present in the blend. The complex viscosity of PLA becomes low at high temperature due to degradation. Hence, the reduction of complex viscosity was observed with the increasing content of PLA in the PBT blend. The complex viscosity reduced dramatically at 50/50 wt\% of PLA/PBT blend ratio.

The storage modulus and loss modulus of the blends correlate well with the complex viscosity results. The storage modulus curves were increased with increasing PLA content due to the presence of PLA droplets that restricted the chains 



Fig. 8 The effect of ESAC compatibilizer on the (a) complex viscosity, (b) storage modulus and (c) loss modulus as a function of angular frequency of PLA/PBT blends.

movement of the PBT. However, the modulus showed a decreasing trend when the content of PLA is more than $30 \mathrm{wt} \%$ in the blends. The increasing dominant phase of PLA in the blends and chains degradation at high temperature cause reduction in the storage and loss modulus.

The effect of ESAC compatibilizer on the shear rheological properties of PLA/PBT blends is shown in Fig. 8. The complex viscosity of the blends was found to increase gradually with the increasing content of ESAC. This observation indicates that the blend was having better intermolecular interactions with the presence of ESAC compatibilizer which restrict the chains movement. ${ }^{61}$

The formation of PLA- $g$-PBT copolymer can be due to the epoxide compatibilization reactions which results in an increase in molecular weight and hence the shear viscosity. ${ }^{34,62}$ In addition, more branched molecular chains were created causing more chain entanglement which leads to an increase in molecular weight and higher viscosity. ${ }^{36,51,52,63}$ The increase in storage modulus and loss modulus after addition of ESAC in the blend confirmed the increased entanglement density. ${ }^{39}$
As mentioned above, the epoxide functional groups in the ESAC compatibilizer can readily react with hydroxyl and carboxyl groups in the end chain of both PLA and PBT which leads to increase in the interaction as well as the chain entanglement between the two polymers. Therefore, the storage modulus and loss modulus increased with the addition of compatibilizer. The presence of ESAC compatibilizer also compensates the molecular weight reduction of PLA at high temperature by induced branch chains during high temperature processing. The $1.0 \mathrm{phr}$ of ESAC showed highest storage modulus and loss modulus as compared to other loadings in the blend.

\subsection{Toughness improvement on PLA/PBT blends with EBA- GMA compatibilizer}

The blending of high content of PLA in PBT decreases the overall impact toughness of the blends due to the brittle nature of PLA. A further toughening approach with elastomer based compatibilizer was implemented to improve the toughness of the blends. It has been widely reported that the glycidyl 

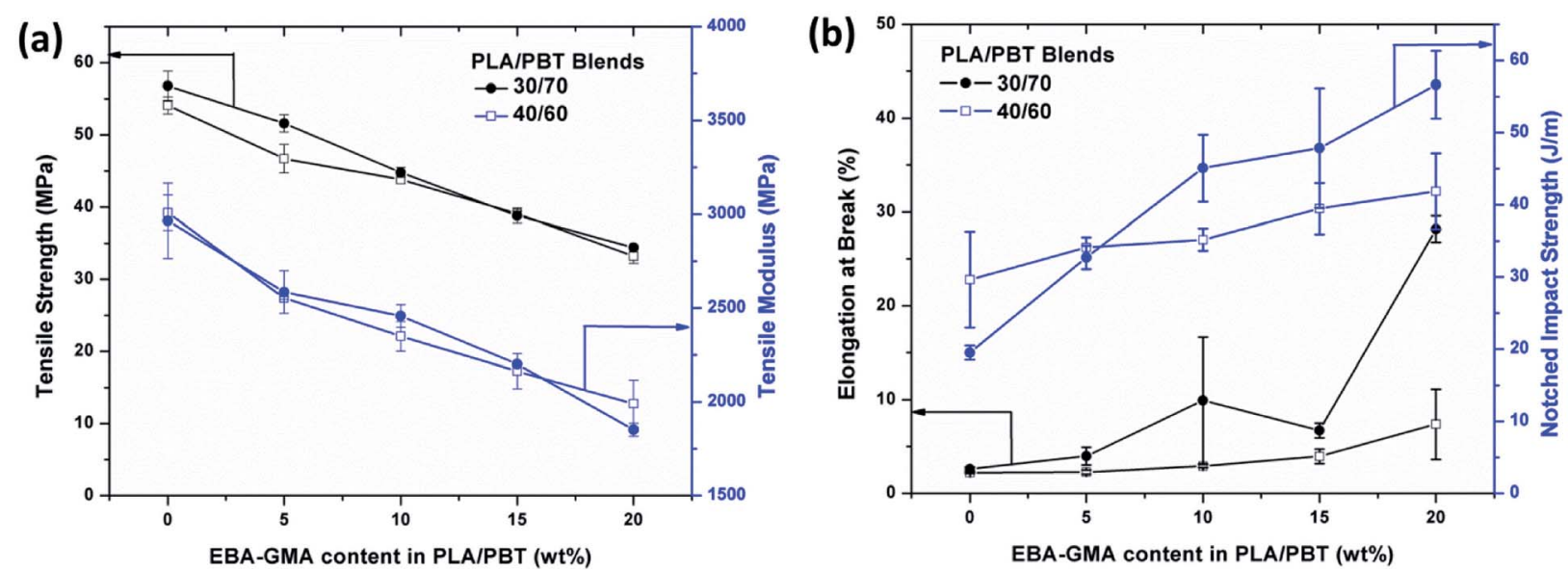

Fig. 9 Effect of EBA-GMA content on the (a) tensile strength and modulus and (b) elongation at break and notched impact strength of the $30 / 70$ and 40/60 PLA/PBT blends.

methacrylate (GMA) based modifier and GMA-grafted polymers can improved the notched impact strength of PBT significantly due to the reaction of the reactive epoxy group with the end functional groups of PBT during processing. ${ }^{13,15,18}$ On the other hand, improvement on notched impact strength of PLA and its blends after blending with ethylene-butyl acrylate-glycidyl methacrylate (EBA-GMA) compatibilizer was reported as well. ${ }^{64,65}$ This indicates that the EBA-GMA functional group can be an effective compatibilizer to react with carboxylic and hydroxyl functional groups of PLA or PBT which can improve their compatibility and toughness after blending. The EBA-GMA compatibilizer containing reactive GMA group is a good compatibilizer ${ }^{66}$ and toughening agent ${ }^{67}$ to improve the properties of the polymer blends.

Fig. 9 presented the tensile properties and impact strength of PLA/PBT blend as a function of EBA-GMA loading. It can be seen that the tensile strength and tensile modulus of the PLA/PBT blends decreased linearly with the increasing content of EBAGMA. The reduction in tensile strength and modulus were due to the presence of elastomeric phase copolymer in the EBAGMA compatibilizer. This soft rubbery phase experiences a high degree of deformation when subjected to mechanical stress. Such observations were widely reported by other researchers after incorporation of EBA-GMA modifier to toughen the polymer. ${ }^{8,10,68}$

Conversely, the blends toughness was improved. The elongation at break and the notched impact strength of the PLA/PBT blends showed an increasing trend with the increasing content of EBA-GMA (Fig. 9b). The increase in elongation at break showed the ductility of the blend was improved after addition of EBA-GMA compatibilizer. The impact strength of the PLA/PBT blend increased approximately two folds from $19.50 \mathrm{~J} \mathrm{~m}^{-1}$ (no EBA-GMA) to $56.6 \mathrm{~J} \mathrm{~m}^{-1}$ at $20 \mathrm{wt} \%$ of EBA-GMA. This can be due to the reduction of average rubber particles distance with increasing content of EBA-GMA which could create continuous craze and shear zone to provide high toughness. ${ }^{17}$ The average notched impact strength of the $20 \%$ EBA-GMA/80\% PBT was approximately $450 \mathrm{~J} \mathrm{~m}^{-1}$. The notched impact strength of the
PLA/PBT blends was also increased after incorporation of EBAGMA. However the increment was not as high as when only homopolymer was used. This might be due to the presence of two phases of the components in the blends as compared to when only single pure PBT or PLA in the system. The morphology structures as well as the interfacial tension in the blends were changed significantly after blending the two polymers as compared to the homopolymer.

The increased in the notched impact strength indicates the EBA-GMA substantially toughens the PLA/PBT blends. Several factors have been discussed for the elastomer toughening mechanism in plastic such as interfacial bonding strength, the diameter of the disperse rubber particles and the distance between the rubber particles. ${ }^{17}$ Through the optimal conditions control, the toughness of the polymer can increase significantly through effective elastomer toughening mechanism. In addition, the reactive epoxy groups of EBA-GMA can act as a compatibilizer by reacting with both carboxylic and hydroxyl groups of polyester through ring opening reaction during melt blending to provide better compatibility and a higher degree of deformation (crazing and shear yielding) which leads to an increase of the impact strength of the blends. ${ }^{17}$

\subsection{Synergistic effect of PLA/PBT blends with ESAC and EBA-GMA compatibilizers}

Hybridization of different compatibilizer has showed promising outcomes in the polymer blends. Lee et $a .^{69}$ have examined the effect of a hybrid compatibilizer of PP- $g$-MAH and PE- $g$-GMA and their single use in affecting the properties of ternary blends of PP, PLA and toughening modifier. They found that with the hybrid compatibilizers the mechanical properties of the blend demonstrated superior performance compared to that of the blend comprising a single compatibilizer. In another work reported by Lin et al. ${ }^{68}$ the amount of acrylic-based modifier used to compatibilize the PBT/PC blend can be reduced from $20 \mathrm{wt} \%$ to $5 \mathrm{wt} \%$ when a transesterification catalyst was added and still 
maintained high impact performance. Fig. 10 shows the comparison of mechanical properties of PLA/PBT blends with single and hybrid compatibilizer used. It can be seen that the tensile strength and modulus of the blends were higher in hybrid compatibilizer system as compared to single compatibilizer (Fig. 10a and b). The presence of ESAC in the compatibilized PLA/PBT/EBA-GMA blends could compensate slightly for the reduction of the tensile strength and modulus. Furthermore, with the presence of both compatibilizers in the blends, the notched impact strength of PLA/PBT blends was increased significantly as compared to with single compatibilizer (Fig. 10c). The blend with 15 wt\% of EBA-GMA loading shows the highest impact strength value for both 30/70 and 40/60 PLA/ PBT ratios.

The notched impact strength of the compatibilized 30/70 PLA/PBT blend increased from $26.3 \mathrm{~J} \mathrm{~m}^{-1}$ (without EBA-GMA) to $47.9,79.7,139.9$ and $119.5 \mathrm{~J} \mathrm{~m}^{-1}$ with $5,10,15$ and $20 \mathrm{wt} \%$ of EBA-GMA in the blends, respectively. While for the 40/60 PLA/ PBT blend, the impact strength increased from $29.7 \mathrm{~J} \mathrm{~m}^{-1}$ (without EBA-GMA) to 46.4, 79.8, 115.3 and $98.4 \mathrm{~J} \mathrm{~m}^{-1}$ with 5, 10,15 and $20 \mathrm{wt} \%$ of EBA-GMA in the blends, respectively. The highest notched impact strength achieved in the blend exhibited a $\sim 433 \%$ and $\sim 288 \%$ increase for $30 / 70$ and $40 / 60$ PLA/PBT blends respectively as compared to the pure blends. The addition of $15 \mathrm{wt} \%$ of EBA-GMA and $1.0 \mathrm{phr}$ of the ESAC in the blends is enough to increase the notched impact strength more than $250 \%$. Interfacial adhesion between blends components is very important to achieve high impact strength. The presence of ESAC might further reduce the surface tension between the blends component and EBA-GMA which resulted in finely dispersed EBA-GMA particles that could effectively improve the impact strength. Furthermore, the degradation of the PLA when processed at high temperature will be minimized with the aid of ESAC compatibilizer. Hence, the impact strength can be further enhanced.

The interface compatibilization of the blend was further investigated with rheometer. The complex viscosity of the blends with only single compatibilizer and hybrid compatibilizer is shown in Fig. 10d. It can be seen that the complex viscosity of the blends were improved after incorporation of the compatibilizer. The highest complex viscosity was observed at the blend with the presence of hybrid compatibilizer. The
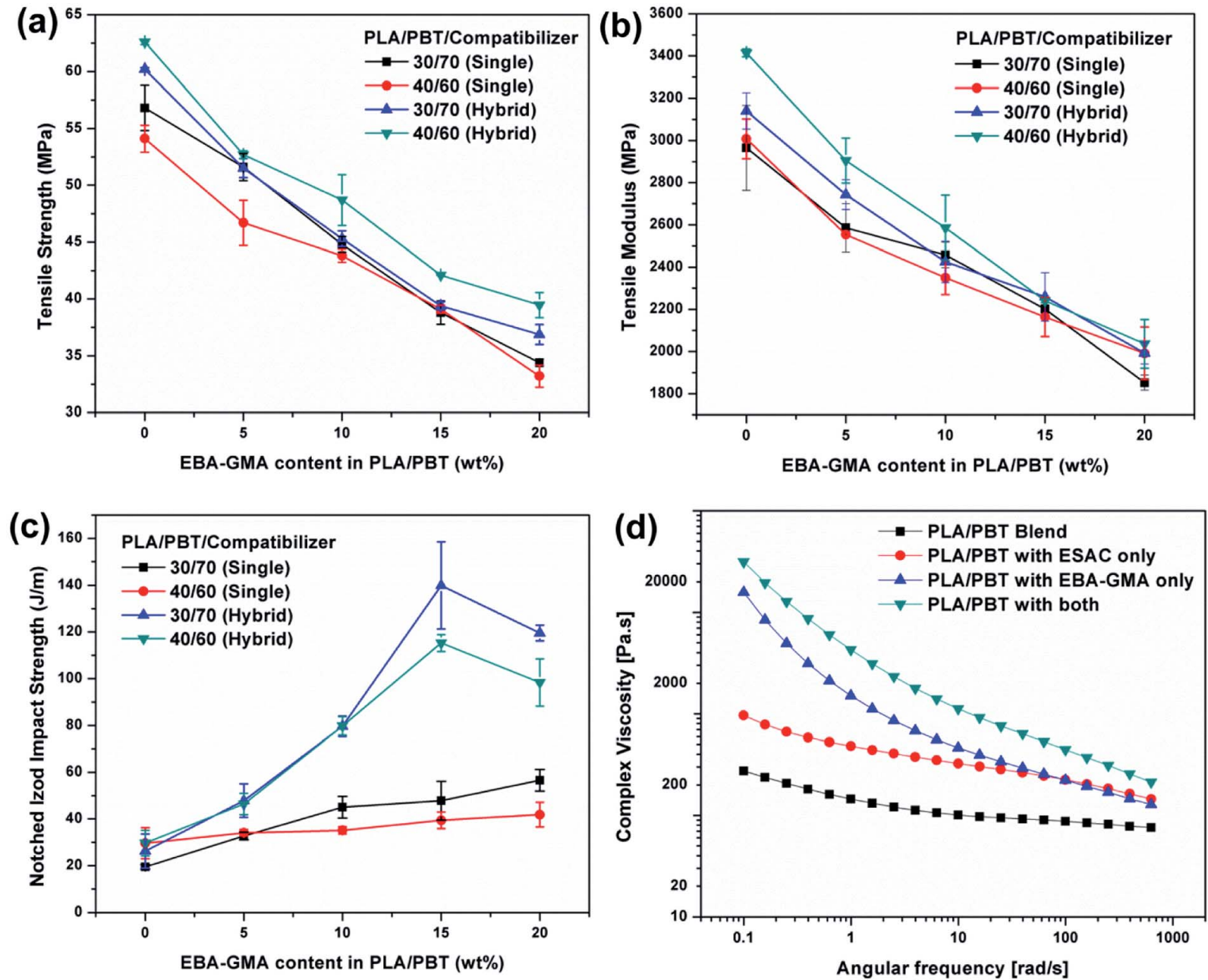

Fig. 10 Effect of single and hybrid compatibilizer system in the PLA/PBT blends on (a) tensile strength (b) tensile modulus, (c) notched impact strength and (d) complex viscosity. 
increase of complex viscosity may be due to the grafting effect and formation of copolymers. ${ }^{\mathbf{7 0 , 7 1}}$ The reactive epoxy functional groups from both compatibilizers can react with the polyester groups of PLA and PBT to form PLA-g-PBT copolymers. The further increase of complex viscosity of the hybrid system corresponds to the effective copolymer formation due to the synergistic effect with the presence of both compatibilizers. As a result, higher complex viscosity can be seen with hybrid compatibilizer in comparison to when a single compatibilizer is use.

\subsection{Impact fractured morphology and AFM observation of compatibilized PLA/PBT blends}

The control and analysis of the polymer blends morphology have become more and more important in the modern polymer processing industry. The comparison on the notched impact strength results and impact fractured morphology of the PLA/ PBT blend with and without compatibilizer are shown in
Fig. 11. It can be seen that without ESAC compatibilizer in the blend, the notched impact strength was improved only slightly even compounded with high loading of EBA-GMA compatibilizer (20 wt\%). This shows that ESAC compatibilizer plays an important role in compatibilized blend to create better stress transfer in the blend. The extent of thermal degradation of PLA during high temperature processing can be reduced to a minimum after addition of the ESAC compatibilizer. The notched impact strength in the PLA/PBT/EBA-GMA increases with the increase of ESAC content. From the inset of SEM impact fractured morphologies comparison, it can be seen that the impact fractured surfaces of the PLA/PBT/ESAC blends without EBA-GMA is relatively flat and smooth (Fig. 11b). The impact fractured surfaces become rougher with uniform rubber dispersion after addition of EBA-GMA (Fig. 11d). This shows that higher energy absorption has occurred during impact testing after the addition of EBA-GMA in the blends. The cavities on the surfaces are due to the rubber particle pull outs upon

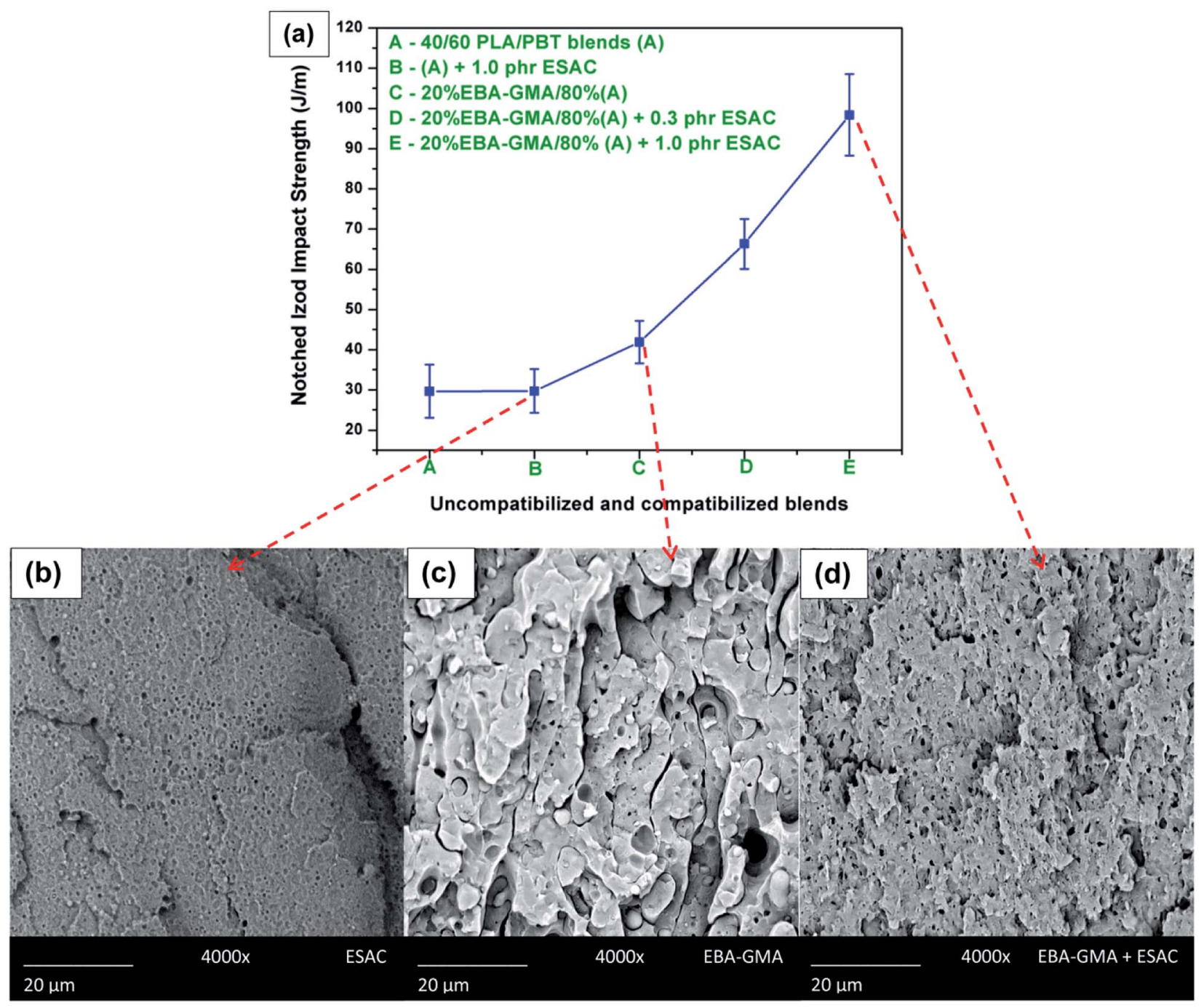

Fig. 11 (a) Notched Izod impact strength of uncompatibilized and compatibilized PLA/PBT blends at different content of ESAC compatibilizer. Bottom inlets are SEM impact fractured surfaces of the blends with single and hybrid compatibilizer (b) only ESAC, (c) only EBA-GMA and (d) with both ESAC and EBA-GMA. 

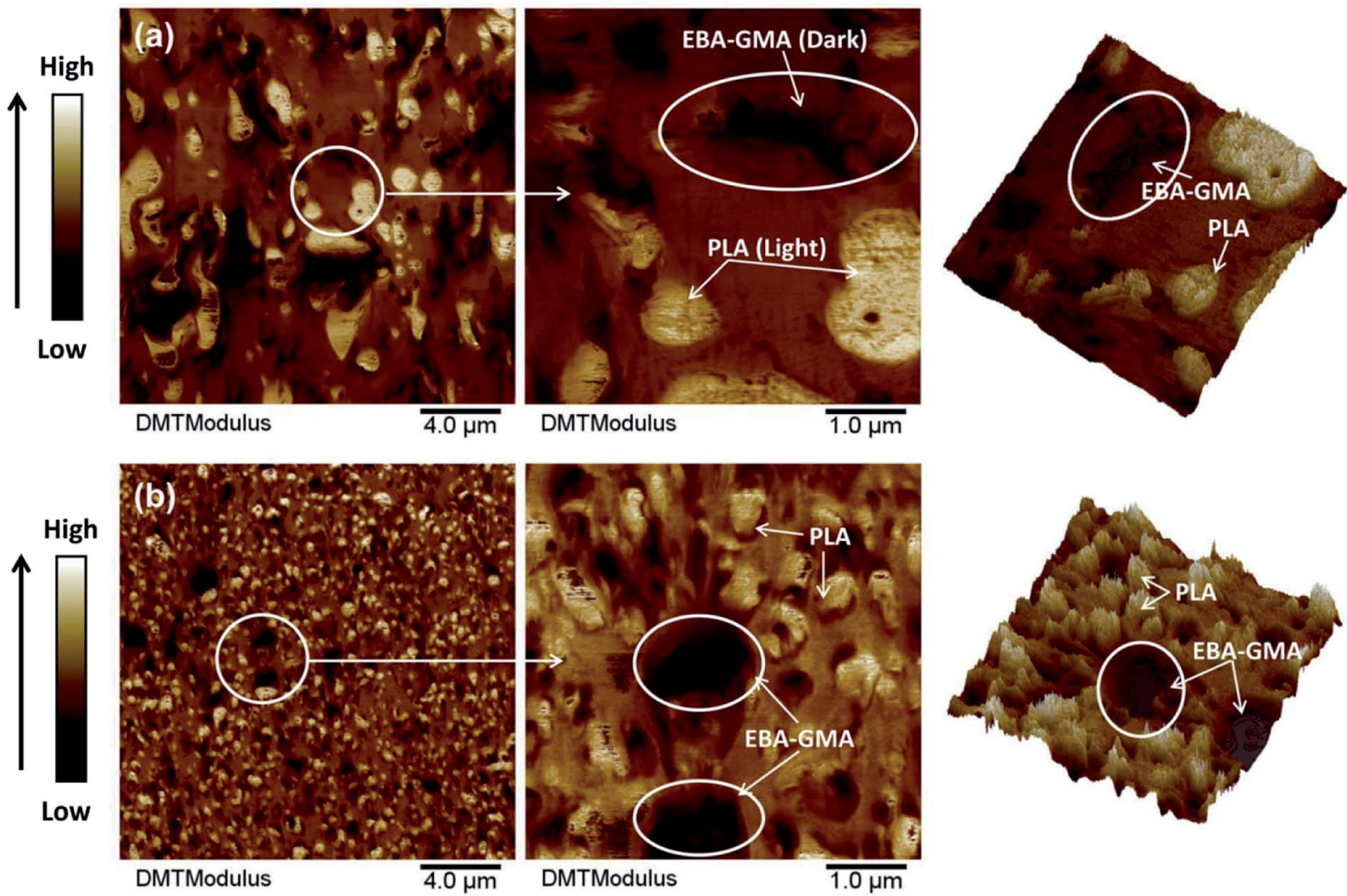

Fig. 12 The AFM topography analysis of the PLA/PBT blends with (a) single compatibilizer (EBA-GMA) and (b) both compatibilizers (ESAC and EBA-GMA).

impact stress. It is clearly observed that the impact fractured surface of the EBA-GMA/PLA/PBT blend without ESAC has larger domains of distinctive polymer phases and non-uniform rubber cavity distribution (Fig. 11c) as compared to the impact fractured surfaces of EBA-GMA/PLA/PBT blend with ESAC (Fig. 11d). The larger interfacial gaps between the polymer domains indicate the poor compatibility between the two polymers. Therefore, the impact strength of the PLA/PBT blend remains low even with high loading of EBA-GMA compatibilizer.

Fig. 12 shows the AFM topography of EBA-GMA compatibilizer and hybrid of EBA-GMA and ESAC compatibilizer in the PLA/PBT blends. The dark colored areas are phases having low modulus, while light colored regions are phases having high modulus. The modulus of the blend component is according to the order of PLA > PBT > EBA-GMA, where PLA exhibits the highest modulus value in the blend. When there is no addition of ESAC compatibilizer, it can be seen that the PLA phases show large domains and are non-uniformly distributed in the PBT (Fig. 12a). In addition, the EBA-GMA phases are also random in structured. With the presence of both compatibilizers, a spherical EBA-GMA copolymer was observed (Fig. 12b). In an ideal case or optimized condition, the EBA-GMA would self-assemble into a spherical structure due to its hydrophilic and hydrophobic end groups (head and tails). The ESAC compatibilizer acts as a catalyst to promote the formation of spherical EBA-GMA structure due to the further reduction of the interfacial tension between components during reactive blending. The formation of spherical EBA-GMA structures shows a significant change with the notched impact strength. This observation is also aligning with the studies reported by Yuryev et al. ${ }^{72}$ They found a dramatic improvement in impact strength of a PLA/EBA-GMA blend due to formation of spherical EBA-GMA structures in the presence of ESAC compatibilizer.

From the AFM topography, the synergizing effects of both compatibilizers in the blend shows a reduction in the PLA droplets size and improved the dispersion of PLA in the PBT phase. This indicates that the synergizing effect of GMA copolymers from both reactive compatibilizers further reduces the interfacial tension between the PLA and PBT phases which suppresses the formation of coalescence of PLA droplets. Therefore, the incorporation of both ESAC and EBA-GMA compatibilizers in the blends was capable to further toughen the blends through effective interfacial reactive compatibilization as compared to single compatibilizer blends system.

\section{Conclusions}

Sustainable biobased polymer blends from PLA and PBT were fabricated and their property enhancements were studied using ESAC and EBA-GMA reactive epoxy functional compatibilizers. It was found that the tensile strength and modulus of the blends increase while the elongation at break and notched impact 
strength decrease with the increasing content of PLA. The full co-continuous phases of PLA in the PLA/PBT blend were confirmed at 50/50 wt\% PLA/PBT blend ratio. The tensile strength, tensile modulus and elongation at break of the blend were improved with the addition of the ESAC compatibilizer. The elongation at break and tensile toughness of the PLA/PBT blends were increased significantly with $1.0 \mathrm{phr}$ of ESAC. The ESAC compatibilizer was found to be effective in improving the toughness at low strain rates (tension test) but not effective at high strain rates (impact test) for the blends. The fractured surfaces of the blends showed less interfacial gap, better dispersion and transition from two distinctive phases to a mild distinct phase with increasing ESAC compatibilizer. At high shear amplitude frequency, the complex viscosity of the PLA/ PBT blends decreased with the addition of PLA in PBT. There are small physical interactions (hydrogen bonding) between PLA and PBT at low shear amplitude. The complex viscosity, storage modulus and loss modulus of the PLA/PBT blends increase with increasing content of the ESAC compatibilizer.

The tensile strength and tensile modulus of the PLA/PBT blends decrease after incorporation of the EBA-GMA compatibilizer. However, the elongation at break and notched impact strength of the blends were improved with the increasing content of EBA-GMA. The enhancement of the mechanical properties of PLA/PBT blends is more pronounced with the presence of both ESAC and EBA-GMA compatibilizers than single compatibilizer blends. The synergistic compatibilizer effect of ESAC and EBA-GMA in the blends contributes to significant enhancement of notched impact strength. An increment of notched impact strength of more than $200 \%$ was obtained in the PLA/PBT blends as compared to the uncompatibilized PLA/PBT blend. The substantial increase in notched impact strength of the blends was due to the further enhancement in interfacial compatibilization between blend components and formation of an effective spherical EMA-GMA structure as evidenced in the AFM topography.

The developed high toughness and sustainable biobased PLA/PBT blend demonstrated high potential to replace the high-volume usage of petroleum based PBT where the dependency on petroleum based resources can be reduced and lead to better sustainable development.

\section{Conflicts of interest}

There are no conflicts to declare.

\section{Acknowledgements}

The authors acknowledge the financial support from Ontario Research Fund, Research Excellence Program; Round-7 (ORFRE07) from the Ontario Ministry of Research Innovation and Science (MRIS) (Project \# 052644 and 052665), The Ontario Ministry of Agriculture, Food and Rural Affairs (OMAFRA)/ University of Guelph Gryphon's LAAIR Program (Project \# 298635) and The Natural Sciences and Engineering Research Council (NSERC), Canada Discovery Grants (Project \# 401111 and 400320).

\section{Notes and references}

1 B. Chisholm and J. Zimmer, J. Appl. Polym. Sci., 2000, 76, 1296-1307.

2 R. N. Baxi, S. U. Pathak and D. R. Peshwe, Polym. J., 2011, 43, 801-808.

3 G. Aravinthan and D. Kale, J. Appl. Polym. Sci., 2005, 98, 7582.

4 J. K. Kim and H. Lee, Polymer, 1996, 37, 305-311.

5 C.-C. Huang and F.-C. Chang, Polymer, 1997, 38, 2135-2141.

6 Y.-T. Shieh, T.-N. Liao and F.-C. Chang, J. Appl. Polym. Sci., 2001, 79, 2272-2285.

7 J. Wu, Y.-W. Mai and A. F. Yee, J. Mater. Sci., 1994, 29, 45104522.

8 H. Bai, Y. Zhang, Y. Zhang, X. Zhang and W. Zhou, Polym. Test., 2005, 24, 235-240.

9 F. J. Vallejo, J. I. Eguiazábal and J. Nazábal, J. Appl. Polym. Sci., 2001, 80, 885-892.

10 A. Aróstegui, M. Gaztelumendi and J. Nazábal, Polymer, 2001, 42, 9565-9574.

11 A. Arostegui and J. Nazabal, Polym. Eng. Sci., 2003, 43, 16911701.

12 E. Hage, W. Hale, H. Keskkula and D. Paul, Polymer, 1997, 38, 3237-3250.

13 S. L. Sun, X. Y. Xu, H. D. Yang and H. X. Zhang, Polymer, 2005, 46, 7632-7643.

14 L. Yang, H. Chen, S. Jia, X. Lu, J. Huang, X. Yu, K. Ye, G. He and J. Qu, J. Appl. Polym. Sci., 2014, 131, 40660.

15 A. Arostegui and J. Nazabal, J. Polym. Sci., Part B: Polym. Phys., 2003, 41, 2236-2247.

16 N. Larocca, E. Hage and L. Pessan, Polymer, 2004, 45, 52655277.

17 C. Zhang and G. Dai, J. Mater. Sci., 2007, 42, 9947-9953.

18 X.-H. Wang, H.-X. Zhang, Z.-G. Wang and B.-Z. Jiang, Polymer, 1997, 38, 1569-1572.

19 J. P. Greene, Sustainable plastics: environmental assessments of biobased, biodegradable, and recycled plastics, John Wiley \& Sons, 2014.

20 E. Bioplastics, Bioplastics market data 2017, Global production capacities of bioplastics, 2017-2022, http:// www.european-bioplastics.org/market/.

21 Y. Yuryev, A. K. Mohanty and M. Misra, RSC Adv., 2016, 6, 105094-105104.

22 G. M. Roudsari, A. K. Mohanty and M. Misra, ACS Omega, 2017, 2, 611-617.

23 Y. Chen, W. Wang, D. Yuan, C. Xu, L. Cao and X. Liang, ACS Sustainable Chem. Eng., 2018, 6, 6488-6496.

24 T.-H. Zhao, W.-Q. Yuan, Y.-D. Li, Y.-X. Weng and J.-B. Zeng, Macromolecules, 2018, 51, 2027-2037.

25 Y. Chen, D. Yuan and C. Xu, ACS Appl. Mater. Interfaces, 2014, 6, 3811-3816.

26 D. Yuan, Z. Chen, C. Xu, K. Chen and Y. Chen, ACS Sustainable Chem. Eng., 2015, 3, 2856-2865.

27 O. Valerio, J. M. Pin, M. Misra and A. K. Mohanty, ACS Omega, 2016, 1, 1284-1295. 
28 M. L. Di Lorenzo, P. Rubino and M. Cocca, Eur. Polym. J., 2013, 49, 3309-3317.

29 R. Von Oepen and W. Michaeli, Clin. Mater., 1992, 10, 21-28.

30 A. Södergård and J. Näsman, Polym. Degrad. Stab., 1994, 46, 25-30.

31 O. Wachsen, K. Platkowski and K.-H. Reichert, Polym. Degrad. Stab., 1997, 57, 87-94.

32 L. Yang, X. Chen and X. Jing, Polym. Degrad. Stab., 2008, 93, 1923-1929.

33 H. J. Lehermeier and J. R. Dorgan, Polym. Eng. Sci., 2001, 41, 2172-2184.

34 L. C. Arruda, M. Magaton, R. E. S. Bretas and M. M. Ueki, Polym. Test., 2015, 43, 27-37.

35 F. Walha, K. Lamnawar, A. Maazouz and M. Jaziri, Polymers, 2016, 8(3), 61.

36 R. Al-Itry, K. Lamnawar and A. Maazouz, Polym. Degrad. Stab., 2012, 97, 1898-1914.

37 N. Najafi, M. C. Heuzey, P. J. Carreau and P. M. WoodAdams, Polym. Degrad. Stab., 2012, 97, 554-565.

38 V. Ojijo and S. S. Ray, Polymer, 2015, 80, 1-17.

39 N. Zhang, C. Zeng, L. Wang and J. Ren, J. Polym. Environ., 2013, 21, 286-292.

40 M. W. Kim, S. M. Hong, D. Lee, K. Park, T. J. Kang and J. R. Youn, Adv. Compos. Mater., 2010, 19, 331-348.

41 J. Zhou, Z. Jiang, Z. Wang, J. Zhang, J. Li, Y. Li, J. Zhang, P. Chen and Q. Gu, RSC Adv., 2013, 3, 18464-18473.

42 L. G. Santos, L. C. Costa and L. A. Pessan, J. Appl. Polym. Sci., 2018, 135, 45951.

43 E. Schwach and L. Averous, Polym. Int., 2004, 53, 2115-2124.

44 Z. Yuan and B. D. Favis, AIChE J., 2005, 51, 271-280.

45 R. Willemse, A. P. De Boer, J. Van Dam and A. Gotsis, Polymer, 1999, 40, 827-834.

46 A. R. McLauchlin and O. R. Ghita, J. Appl. Polym. Sci., 2016, 133, 44147.

47 V. Nagarajan, A. K. Mohanty and M. Misra, ACS Sustainable Chem. Eng., 2016, 4, 2899-2916.

48 N. Najafi, M. C. Heuzey and P. J. Carreau, Compos. Sci. Technol., 2012, 72, 608-615.

49 L. Gwo-Geng, S. Hsi-Hsin, C. Ping-Chang and H. Shio-Jin, Polym. Eng. Sci., 2002, 42, 2213-2221.

50 W. Dong, B. Zou, Y. Yan, P. Ma and M. Chen, Int. J. Mol. Sci., 2013, 14, 20189.
51 F. Walha, K. Lamnawar, A. Maazouz and M. Jaziri, Polymers, 2016, 8, 61.

52 R. Al-Itry, K. Lamnawar and A. Maazouz, Rheol. Acta, 2014, 53, 501-517.

53 Y.-M. Corre, J. Duchet, J. Reignier and A. Maazouz, Rheol. Acta, 2011, 50, 613-629.

54 S. Japon, L. Boogh, Y. Leterrier and J. A. E. Månson, Polymer, 2000, 41, 5809-5818.

55 K. Lamnawar and A. Maazouz, Rheol. Acta, 2006, 45, 411-424.

56 K. Lamnawar, A. Baudouin and A. Maazouz, Eur. Polym. J., 2010, 46, 1604-1622.

57 Y. Zhang, X. Yuan, Q. Liu and A. Hrymak, J. Polym. Environ., 2012, 20, 315-325.

58 W. R. Hale, L. A. Pessan, H. Keskkula and D. R. Paul, Polymer, 1999, 40, 4237-4250.

59 M. Mehrabi Mazidi, A. Edalat, R. Berahman and F. S. Hosseini, Macromolecules, 2018, 51, 4298-4314.

60 A. Codou, A. Anstey, M. Misra and A. K. Mohanty, RSC Adv., 2018, 8, 15709-15724.

61 N. Zhang, Q. Wang, J. Ren and L. Wang, J. Mater. Sci., 2009, 44, 250-256.

62 Q. Meng, M.-C. Heuzey and P. J. Carreau, Polym. Degrad. Stab., 2012, 97, 2010-2020.

63 R. Al-Itry, K. Lamnawar and A. Maazouz, Eur. Polym. J., 2014, 58, 90-102.

64 H. Kang, X. Lu and Y. Xu, Polym. Test., 2015, 43, 173-181.

65 B.-U. Nam and B.-S. Lee, J. Korea. Acad. Industr. Coop. Soc., 2012, 13, 919-925.

66 S. H. Jafari, A. Asadinezhad, A. Yavari, H. A. Khonakdar and F. Böhme, Polym. Bull., 2005, 54, 417-426.

67 K. Zhang, V. Nagarajan, M. Misra and A. K. Mohanty, ACS Appl. Mater. Interfaces, 2014, 6, 12436-12448.

68 G.-P. Lin, L. Lin, X.-L. Wang, L. Chen and Y.-Z. Wang, Ind. Eng. Chem. Res., 2015, 54, 1282-1291.

69 H. S. Lee and J. D. Kim, Polym. Compos., 2012, 33, 1154-1161. 70 Y. T. Sung, M. S. Han, J. C. Hyun, W. N. Kim and H. S. Lee, Polymer, 2003, 44, 1681-1687.

71 J. S. Borah and T. K. Chaki, J. Polym. Res., 2011, 18, 907-916. 72 Y. Yuryev, A. K. Mohanty and M. Misra, Macromol. Mater. Eng., 2016, 301, 1443-1453. 